An edited version of this paper was published by AGU. Copyright (2008) American Geophysical Union

Peggy M. Vermeesch and Joanna V. Morgan (2008) Structural uplift beneath the Chicxulub impact crater JOURNAL OF GEOPHYSICAL RESEARCH, VOL. 113, B07103, doi:10.1029/2007JB005393, 2008

To view the published open abstract, go to http://dx.doi.org and enter the DOI

\title{
Structural uplift beneath the Chicxulub impact structure
}

Peggy M. Vermeesch ${ }^{1}$ and Joanna V. Morgan ${ }^{2}$

1) Institute for Geophysics, Jackson School of Geosciences, University of Texas at Austin, Texas 78758, USA

2) Department Earth Science and Engineering, Imperial College London, SW7 2AZ, UK

\begin{abstract}
Models of the central structure of large impact craters are poorly constrained, partly due to the lack of well-preserved terrestrial examples, and partly because of the extreme nature of impact events. Even large impact craters take only a few minutes to form, during which time rocks from the deep crust move upwards many kilometers, interacting with impact melts and breccias before settling to their final position. We construct a new model of central uplift beneath the Chicxulub crater, based upon a well-constrained 3D velocity model, obtained by jointly inverting seismic travel-time and gravity data. The input tomographic dataset has good resolution and many rays cross the central uplift in many directions. We use laboratory measurements to convert between velocity and density. Our velocity model possesses a highvelocity-zone near the crater center, and velocity gradually decreases outside this zone. We use regional refraction data to interpret these velocities in terms of a broad 80-km-wide zone of structural uplift, in which the central rocks originate from the lower crust, and the surrounding rocks from the mid and upper crust. This is in contrast with previous models in
\end{abstract}


which the zone of central uplift is either $40-50 \mathrm{~km}$ or $150 \mathrm{~km}$ wide. Our interpretation is consistent with: scaling laws, Yucatán basement lithology, other velocity data, observations at similar-sized terrestrial craters, and dynamic modeling of peak ring formation. Our model of the uplift at Chicxulub can be used to help distinguish between competing models of effective target strength in numerical models of crater formation.

Keywords: Chicxulub, impact crater, 3D velocity model, seismic tomography, inversion

\section{INTRODUCTION}

Although meteorite impacts are a ubiquitous and fundamental geologic process affecting the terrestrial planets, the precise dynamics and kinematics of the processes involved in the formation of large impact craters are still poorly understood. Detailed knowledge of the geometric properties of the central uplift is necessary to constrain dynamic models of impact crater formation. Compared to the geologically less active moon and other planets and satellites throughout the solar system, the Earth has few pristine craters, and only three large ( $>150 \mathrm{~km}$ diameter) confirmed impact basins: Chicxulub, Vredefort and Sudbury, of which Chicxulub is the best preserved. In the first few tens of seconds after impact, a cavity $\sim 100$ $\mathrm{km}$ wide and $25 \mathrm{~km}$ deep was formed and surrounded by mountains the height of Everest [e.g. Ivanov, 2005]. In the next few hundred seconds this transient cavity collapsed to form a 180$200 \mathrm{~km}$ diameter multi-ring basin, with an inner ring (peak ring) that emerged several hundred meters to form a topographic high, and a zone of central uplift. The main focus of this paper is on the central uplift. Geological investigation of terrestrial complex craters shows that their central uplifts are composed of deformed and fractured rocks that originally underlay the transient crater. Horizontal strata are initially pushed downward during the compressive stage of impact, and then stratigraphically uplifted by a certain distance above their initial depth before they collapse to their final position. 
The Chicxulub impact occurred $65 \mathrm{Ma}$ ago on a stable carbonate platform, which comprised $\sim 3 \mathrm{~km}$ of Cretaceous carbonates above Paleozoic basement rocks [Hildebrand et al., 1991]. The Chicxulub impact breccias contain clasts of basement rock that are predominantly granitic and gneissic [Sharpton et al., 1996; Kettrup and Deutsch, 2003; Vermeesch, 2006] and are likely to originate from the upper Yucután crust. The lithology and metamorphic grade of the lower crust is unknown, but is likely to be more mafic than upper crust as velocity increases with depth [Christeson et al., 2001; Christensen and Fountain, 1975]. The crater floor is covered with shock-melted rocks and impact breccias, that are thought to be a few kilometers thick in the central basin [Hildebrand et al., 1991; Kring, 1995; Sharpton et al., 1996]. The crater has subsequently been buried and now lies beneath up to $2 \mathrm{~km}$ of Tertiary sedimentary rocks. Seismic reflection data acquired across the offshore half of the Chicxulub crater in 1996 and 2005 (Fig. 1) allow us to image the lithologies outside the impact basin, corresponding to the original target of the Chicxulub impact, as well as the lithologies within the impact basin [e.g. Morgan et al., 1997; Gulick et al., 2008]. There are no reflection data across the crater center, and therefore central crater structure at Chicxulub, and large impact craters in general, is a matter of some debate.

In the central region of large impact craters, we observe central uplifts, peak rings, melt sheets and impact beccias. The precise geometry, extent and potential overlap of these features remain uncertain. Models of Chicxulub constructed from geophysical data are diverse [e.g. Sharpton et al., 1996; Hildebrand et al., 1998; Vermeesch and Morgan, 2004] in part due to the lack of terrestrial examples and the inherent ambiguity of potential-field modeling, and also because drill holes within the impact basin have penetrated the uppermost crater deposits only. For example, in the model of Sharpton et al. [1996] the central uplift is broad, with 
uplift in upper-crustal rocks continuing out to $150 \mathrm{~km}$ diameter, and with uplifted lower crust forming a 100-km diameter peak ring (Fig. 2a). In the model by Hildebrand et al. [1998] the central uplift is relatively narrow ( $\sim 50 \mathrm{~km}$ in diameter), surrounded by megabreccia (defined as allogenic polymict breccia containing clasts of target rock from several stratigraphic levels in Visnevsky and Montanari [1999]), and separated from the peak ring by megabreccia and/or melt sheet (Fig. 2b). In other geophysical models of central crater structure, the central gravity high and/or magnetic anomalies are modeled with a narrow zone of central uplift of a similar width to the model in Fig. 2b [e.g. Espindola et al., 1995; Campos-Enriquez et al., 1998; Ebbing et al., 2001].

Some of the features of the Sharpton et al. [1996] model in Fig. 2a were shown to be incorrect with the acquisition of the 1996 seismic reflection survey (Fig. 1). For example the Cretaceous sedimentary rocks can be tracked to within $\sim 40 \mathrm{~km}$ of the crater center, and lie several kilometers beneath the peak ring [Morgan et al., 1997]. Hence the zone of structural uplift must be narrower than the $150 \mathrm{~km}$ diameter depicted in Fig. 2a. However, the narrow zone of central uplift surrounded by megabreccia in the model of Fig. $2 b$ is inconsistent with observations at two similar-sized large terrestrial craters: Vredefort and Sudbury. The Vredefort dome is $\sim 80 \mathrm{~km}$ wide, and comprises a $40 \mathrm{~km}$ diameter Archean core of deep crustal rocks surrounded by an annular collar of mid-crustal rocks [Gibson et al., 1998; Lana et al., 2003]. At Sudbury there is also a decrease in metamorphic grade with distance from the Sudbury Igneous Complex (SIC) [Riller, 2005; Grieve et al., 2008]. The erosion level at Vredefort is postulated to be around 5-10 km [McCarthy et al., 1990; Gibson and Reimold, 2001], and a few kilometers outside the SIC at Sudbury [Dressler, 1984]. Neither of these craters contains a zone of megabreccia, which would be $>10 \mathrm{~km}$ in width if the model of Fig. $2 \mathrm{~b}$ were applicable to all large terrestrial impact craters. A narrow zone of megabreccia is 
observed at the smaller Popigai crater, but models of this crater suggest that the megabreccia is a near-surface feature only [Visnevsky and Montanari, 1999] and does not extend to great depths. Hence the zone of central uplift at Chicxulub must be narrower than shown in Fig. 2a and it is unlikely to be surrounded by large volumes of megabreccia as shown in Fig. $2 b$.

The 1996 seismic refraction data (Fig. 1) revealed strong changes in seismic velocity across the crater, with a low-velocity-zone (LVZ) beneath the peak ring and a high-velocity-zone (HVZ) close to the crater center [Morgan et al., 2000; Christeson et al., 2001; Vermeesch and Morgan, 2004]. Resolution testing suggested that the final velocity model was robust in areas of good ray coverage [Morgan et al., 2002], and that the top of the HVZ had a concave upward shape along well-constrained profiles. In 2005 we acquired a more extensive 3D refraction dataset of $\sim 3.8$ million marine shots fired on a grid of 11 ENE-WSW and 10 NNWSSE oriented reflection lines and recorded on 48 offshore and 67 onshore seismometer sites. These tomographic refraction data were acquired to provide constraints on central crater structure that far exceed those obtainable from potential-field data.

In this paper we present $3 \mathrm{D}$ velocity models of the central crater at Chicxulub, determined by inverting both the 1996 and 2005 seismic refraction data, and including constraints from gravity. We use our velocity models to make a geological interpretation of structural uplift beneath the crater.

\section{METHOD}

Prior to inverting the 1996 and 2005 data, Vermeesch [2006] and Vermeesch et al. [2008] ran a suite of inversions on a synthetic velocity model of the central uplift at Chicxulub. This involved forward modeling of the seismic waves, using the same shot and receiver locations 
as in the real data, and inverting the resulting travel-times to recover the original velocity model. These tests showed that travel-time inversions produced accurate models of the central uplift down to $\sim 6 \mathrm{~km}$ depth, but could not resolve structure at depths greater than $\sim 7 \mathrm{~km}-$ the maximum penetration depth of the modeled ray paths. A suite of checkerboard tests [Yhap, 2007] also confirmed that the velocity model was well constrained down to depths of 6-7 km. Using laboratory measurements on samples from the Yaxcopoil-1 core (Fig. 1) to convert between velocity and density, Vermeesch [2006] and Vermeesch et al. [2008] discovered that a combined travel-time and gravity inversion tended to resolve the upper part of the structural uplift less well than the travel-time inversion alone, but could partially resolve the deeper velocity structure, as well as velocities in other areas with limited ray coverage. We have thus run two separate inversions on the real data: the first uses travel-times only, and the second uses both the travel-time and gravity data. These synthetic tests and checkerboard resolution tests suggest that we should use the results of the travel-time inversion in areas of good ray coverage and up to $6 \mathrm{~km}$ depth, and the combined inversion elsewhere to construct a final model.

\section{Travel-time inversion only}

We used the 3D version of the FAST (First Arrival Seismic Tomography) code, which is an iterative tomographic inversion developed by Zelt and Barton [1998]. In our 1D starting velocity model, velocities are defined over 500-m length cubes, in a 3D volume that is 110 $\mathrm{km} \times 100 \mathrm{~km}$ and $15 \mathrm{~km}$ in depth. First-arrival travel-times have been picked for 375,787 shot-receiver pairs. The majority were assigned a picking error of $50 \mathrm{~ms}$, and the remainder an error of $100 \mathrm{~ms}$. In FAST the objective function includes a term for both data misfit and model roughness, and the only free parameters are $\mathrm{Sz}$ and $\alpha$. Sz can be used to place constraints on vertical smoothness, and $\alpha$ is a trade-off parameter that controls the relative 
weighting between fitting the observed data with: 1) a minimally perturbed velocity model, that minimizes the difference between the starting and inverted velocity models $(\alpha=0)$, and 2) a smooth model $(\alpha=1)$. The rationale for regularizing the inversion in this way is to find models that fit the data adequately well, but avoid introducing structure that may not exist. The final velocity model was determined using $\mathrm{Sz}=0.2$ and $\alpha=0.9$, which allows velocities to change rapidly in the vertical direction, and regularizes the inversion to weight towards a smooth model. These values for $\mathrm{Sz}$ and $\alpha$ were used as they led to the best recovery of the central uplift in the synthetic tests [Vermeesch, 2006].

\section{Combined travel-time and gravity inversion}

We have adapted the FAST code to include constraints from the gravity data [Vermeesch, 2006; Vermeesch et al., 2008]. The gravity data were filtered to remove the regional gradient and then sampled on a $4 \mathrm{~km}$ grid spacing. Gravity data from the NW and SE corner were excluded from the inversion, as it was considered likely that at least part of the gravity signal here was sourced from outside the modeled volume. 327 gravity values were included in the inversion. The data misfit is calculated using both the gravity and travel-time misfit, and there is an extra step to convert between slowness (1/velocity) and density. We have used a suite of measurements [Vermeesch and Morgan, 2004] on core from drill holes within the post-impact sedimentary rocks, Cretaceous target rocks and impact breccias, to determine a best-fit equation for the conversion: density $\left(\right.$ in $\mathrm{kg} \mathrm{m}^{-3}$ ) $=-3478 \times$ slowness $\left(\right.$ in $\left.10^{3} \mathrm{~s} \mathrm{~m}^{-1}\right)+3326$ [Vermeesch, 2006; Vermeesch et al., 2008]. We have used a relatively large uncertainty of 1 mgal for the gravity ( $\sim 5 \%$ of the total anomaly) as we do not wish to over-fit the gravity data, given that the conversion from slowness to density is not exact, our conversion equation may not be appropriate for deeper rocks for which we have no samples, and part of the gravity anomaly may come from density differences deeper than $15 \mathrm{~km}$. The inversion was run using 
free parameters $\mathrm{Sz}=5.0$ and $\alpha=1.0$, as these values led to the best recovery of the central uplift in the synthetic tests [Vermeesch, 2006].

\section{RESULTS}

We haven taken several 2D slices of our 3D velocity model, of which some cross the nominal crater center at $\mathrm{X}=0 \mathrm{~km}=\mathrm{Y}$, and some image the location of highest velocity at $\mathrm{X}=-12 \mathrm{~km}$ and $\mathrm{Y}=4 \mathrm{~km}$ (Fig. 3 and 4). The highest velocities in the top of the HVZ are 6.4 and $6.5 \mathrm{~km}$ $\mathrm{s}^{-1}$ for the travel-time model and combined model respectively.

In the travel-time inversion the final velocity model (Fig. 3a and 4a) was obtained after 18 non-linear iterations and has a Root Mean Square (RMS) misfit of $83 \mathrm{~ms}$, compared to 170 ms for the starting model. The final model contains a $\mathrm{HVZ}$ of $>6.3 \mathrm{~km} \mathrm{~s}^{-1}$ at $4.5-6.0 \mathrm{~km}$ depth. This HVZ is twin-peaked in some slices (e.g. Fig. 3a at $\mathrm{X}=0 \mathrm{~km}$ and Fig. $4 \mathrm{a}$ at $\mathrm{Y}=8 \mathrm{~km}$ ), resulting in a concave upward $25-\mathrm{km}$ wide top, and single-peaked in other slices (e.g. Fig. 4a at $\mathrm{Y}=4 \mathrm{~km}$ ), resulting in a concave downward $15-\mathrm{km}$ wide top. The maximum recovered velocity is $\sim 6.4 \mathrm{~km} \mathrm{~s}^{-1}$ and occurs at a depth of $6.5 \mathrm{~km}$ at $\mathrm{X}=-12.5 \mathrm{~km}$ and $\mathrm{Y}=3 \mathrm{~km}$.

The final velocity model from the joint travel-time and gravity inversion (Fig. 3b and 4b) was obtained after 10 non-linear iterations and has a RMS misfit of $82 \mathrm{~ms}$ and $0.76 \mathrm{mgal}$, compared to $170 \mathrm{~ms}$ and $6.3 \mathrm{mgal}$ for the starting model. A HVZ of $>6.3 \mathrm{~km} \mathrm{~s}^{-1}$ extends from between 4 and $7.5 \mathrm{~km}$ depth to the base of the model. The top of this HVZ has a complex 3D shape: it is twin-peaked and concave upward in some slices (e.g. Fig. $3 \mathrm{~b}$ at $\mathrm{X}=0 \mathrm{~km}$ and Fig. $4 \mathrm{~b}$ at $\mathrm{Y}=8 \mathrm{~km}$ ) and concave downward in others (e.g. Fig. $4 \mathrm{~b}$ at $\mathrm{Y}=0 \mathrm{~km}$ ). The width of the $\mathrm{HVZ}$ of $>6.3 \mathrm{~km} \mathrm{~s}^{-1}$ varies from $15-25 \mathrm{~km}$ at $6 \mathrm{~km}$ depth in the EW-oriented slices to $35 \mathrm{~km}$ at the bottom of the model in the same slices (Fig. $4 \mathrm{~b}$ ). The maximum recovered velocity is $>6.7$ 
$\mathrm{km} \mathrm{s}^{-1}$ and occurs between depths of 10 to $12 \mathrm{~km}$.

\section{DISCUSSION}

We have inverted a dense 3D tomographic refraction dataset to image subsurface velocity structure at Chicxulub. Our final velocity models are consistent with previous geophysical models, which all contain a 40-50 km-wide dense and/or highly magnetized body [Espindola et al., 1995; Sharpton et al., 1996; Hildebrand et al., 1998; Campos-Enriquez et al., 1998; Pilkington and Hildebrand, 2000; Ebbing et al., 2001] close to the location of the zone of high velocity in Fig. 3 and 4. However, the resolving power of our 3D tomographic refraction data far exceeds that of potential-field data which is inherently underdetermined [e.g. Menke and Abbott, 1991]. Our velocity models have been tested for reliability and robustness [Vermeesch, 2006; Yhap, 2007; Vermeesch et al., 2008] and, unlike other geophysical models, we start with a 1D model of velocity increasing with depth (Fig. 5), hence all horizontal structure in our final velocity models is objectively determined and data driven.

So far nobody has modeled Chicxulub by simultaneously inverting two different and independent types of geophysical datasets. Hence one final advantage of our approach is that we have jointly inverted travel-time and gravity data, hereby deriving a model that fits two independent datasets which have previously given non-consistent results [Vermeesch and Morgan, 2004]. Hence, we are able to make a more confident geological interpretation of central uplift beneath the crater than has previously been possible.

We have updated our geological interpretation of the Chicxulub crater (Fig. 6). The geometry of the post-impact sedimentary rocks, peak ring, Cretaceous target rocks and top of the impact melt sheet have been previously mapped using seismic reflection data, and the thickness of 
the melt sheet has been nominally set at $\sim 2.5-3 \mathrm{~km}$ on the basis that the melt thickness should be similar to the Sudbury crater [Morgan et al., 2000; Morgan et al., 2002]. Our interpretation of the location of upper, mid and lower crustal rocks is new and based upon the velocity models in Fig. 3 and 4. Our model is plotted in the same sketch form and scale as the earlier models in Fig. 2 for easy comparison. For this interpretation we assume that the deep velocity contours were sub-horizontal prior to impact, and use the velocity models in Fig. 3 and 4 to locate the position of uplifted rocks in the central crater. We only interpret structure below 5-km depth because, at these depths, refraction velocities will principally reflect lithology, and not be unduly affected by fracturing. Fractures close under compression, and cease to affect velocity at the expected confining pressures for rocks at these depths [Birch, 1960]. In addition, in travel-time inversions, refraction velocities are averaged across a Fresnel zone, which is of the order of $2 \mathrm{~km}$ at $5 \mathrm{~km}$ depth. Hence, small-scale structures such as pseudotachylite veins, observed in central uplifts at other impact craters, will have a minimal effect on refraction velocity (much less that the changes of a few $\mathrm{km} \mathrm{s}^{-1}$ observed in our velocity model across the central uplift).

Outside the impact basin, refraction velocities rise above $6.0 \mathrm{~km} \mathrm{~s}^{-1}$ at around $8 \mathrm{~km}$ depth, and above $6.3 \mathrm{~km} \mathrm{~s}^{-1}$ at around $15 \mathrm{~km}$ depth [Christeson et al., 2001]. We nominally divide the rocks into upper crustal $\left(<6.0 \mathrm{~km} \mathrm{~s}^{-1}\right)$, mid crustal $\left(>6.0\right.$ and $\left.<6.3 \mathrm{~km} \mathrm{~s}^{-1}\right)$ and lower crustal $\left(>6.3 \mathrm{~km} \mathrm{~s}^{-1}\right)$, so that we can examine the shape of the uplifted rocks from different stratigraphic levels. We interpret the top of the $\operatorname{HVZ}\left(>6.3 \mathrm{~km} \mathrm{~s}^{-1}\right)$ as representing relatively intact and unaltered lower-crustal rocks, although we recognize that altered and/or fractured lower crustal rocks may lie directly above this contour. The HVZ is twin-peaked and concave upwards in some directions, whereas in other directions it is narrower and concave downward. In all directions this HVZ is highly asymmetric (Fig. 3 and 4) and we conclude that the top of 
the intact uplifted lower crust has a complex 3D shape in contrast to the flat top of uplift proposed by Hildebrand et al. [1998]. The width of structural uplift is $15-25 \mathrm{~km}, 40-60 \mathrm{~km}$ and $\sim 80 \mathrm{~km}$ for the lower-, mid- and upper-crustal rocks respectively (Fig. 6). Below we outline how our geological interpretation is consistent with: scaling laws, the lithology of the Yucatán basement, global velocity data, observations at the similar-sized Sudbury and Vredefort craters, and dynamic modeling of peak ring formation.

Grieve and Pilkington [1996] defined an empirical scaling relationship for the maximum structural uplift (SU) for terrestrial craters in terms of apparent crater diameter (D): $\mathrm{SU}=$ $0.086 \mathrm{D}^{1.03}$, and similarly Ivanov et al. [1982] proposed that: $\mathrm{SU}=0.1 \mathrm{D}$. In the Hildebrand et al. [1998] model in Fig. $2 \mathrm{~b}$ the crater diameter is $180 \mathrm{~km}$. Although the crater diameter is larger in the Sharpton et al. [1996] model in Fig. 2a, a later paper agreed on a 180-200 km diameter [Morgan et al., 1997]. Using $\mathrm{D}=180-200 \mathrm{~km}$ and the scaling laws above, the maximum amount of vertical uplift of rocks above their initial depth is estimated to be between 18 and $20 \mathrm{~km}$. The elevation of the $6.3 \mathrm{~km} \mathrm{~s}^{-1}$ velocity contour from $15 \mathrm{~km}$ depth outside the impact basin to $5 \mathrm{~km}$ depth in the crater center indicates a structural uplift of at least $10 \mathrm{~km}$ [Christeson et al., 2001]. The Moho is located at 33-36 km depth beneath Chicxulub, and the Moho close to the crater center is uplifted by $\sim 2 \mathrm{~km}$ [Christeson et al., 2008]. The small topographic changes at the Moho imply that the maximum structural uplift at Chicxulub is restricted to lie within the crust, and must be less than $\sim 30 \mathrm{~km}$. Hence the maximum structural uplift at Chicxulub is between 10 and $30 \mathrm{~km}$, in agreement with scaling laws.

The Chicxulub impact site comprised $\sim 3 \mathrm{~km}$ of Cretaceous sedimentary rocks above Paleozoic basement [Lopez-Ramos, 1979]. Clasts of basement rocks can be found in impact 
breccias within and close to the Chicxulub impact basin (Yaxcopoil-1 and Yucatan-6 drill holes), and are predominantly granitic and gneissic ( $>90 \%)$, and occasionally granulitic [e.g. Sharpton et al., 1996; Kettrup and Deutsch, 2003; Vermeesch, 2006; Vermeesch et al., 2008]. The maximum excavation depth for a crater of this size is estimated to be around $10 \mathrm{~km}$ depth according to scaling laws [Melosh, 1989], and hence the basement clasts in the impact breccia must originate from the upper Yucatán crust. These clasts are typical of silica-rich upper continental crust which, at continental shelves, has a global average velocity of around $6.0 \mathrm{~km}$ $\mathrm{s}^{-1}$ [Mooney et al., 1998]. Refraction velocities of $>6.3 \mathrm{~km} \mathrm{~s}^{-1}$ observed beneath $5 \mathrm{~km}$ depth in our velocity model are typical of more mafic crustal rocks, and should therefore have originated from deeper than the $10 \mathrm{~km}$ excavation depth, in accordance with our suggestion that they are lower crustal.

There are two other large terrestrial craters of comparative size to Chicxulub: Vredefort and Sudbury. A range of size estimates has been made for both craters, but a recent detailed structural comparison [Grieve et al., 2007] places all three craters at around the same size. The impact melt sheet (SIC) and post-impact sedimentary rocks are intact at Sudbury, but the structure has been deformed, and outside the SIC the allochthonous impact breccias have been eroded. Immediately outside the SIC the rocks are granulite facies gneisses, that are interpreted to have been exhumed from an original depth of $\sim 30 \mathrm{~km}$ [James et al., 1992]. Exterior to these gneisses are granite-greenstones of a lower metamorphic grade [Riller, 2005; Grieve et al., 2007]. The Vredefort dome is $\sim 80 \mathrm{~km}$ in diameter, and comprises a $40 \mathrm{~km}$ diameter Archean core of deep crustal rocks, surrounded by an annular collar of mid-crustal rocks [Gibson et al., 1998; Lana et al., 2003]. Hence, observations at both Sudbury and Vredefort suggest that there is a large amount of structural uplift in the central zone, and that the amount of structural uplift decreases outwards. This pattern has also been observed at 
smaller complex craters [Fig. 7 in Grieve, 2006], hence our model of an increase in structural uplift towards the crater center beneath Chicxulub is in accordance with observations at other terrestrial craters. The total width of structural uplift at Vredefort is $80 \mathrm{~km}$, and similar to our estimates for Chicxulub. This might suggest that these two craters were of a similar size. However, if Chicxulub were eroded to $10 \mathrm{~km}$ depth, as suggested for Vredefort [McCarthy et al., 1990], the width of uplift would be estimated at $\sim 60 \mathrm{~km}$ (Fig. 6) and Chicxulub would be considered to be smaller than Vredefort. Without accurate information on original crustal depths and erosion levels at Vredefort, it is difficult to make comparisons of the structural uplift at Vredefort and Chicxulub. In addition, the kinematics of uplift in dynamic models is highly dependent on target strength, and variations in target strength with depth [e.g. Wünnemann et al., 2005]. Hence, the mechanics of crater formation could be quite different for these two craters.

Dynamic models of the formation of the Chicxulub crater [O'Keefe and Ahrens, 1999; Collins et al., 2002; Ivanov, 2005] all show a zone of structural uplift in the crater center with total uplift decreasing outwards and downwards, and overturning of upper crustal rocks to form a topographic peak ring. The location and geometry of the overturning of the upper/mid crustal boundary shown in Fig. 6 is closely replicated in dynamic models by Collins et al. [2002; 2008], but the shape and extent of lower crustal uplift is less well matched. The effective strength of crust and mantle rocks during large impacts is not well understood, but must be substantially lower than typical static strength measurements of rock [Melosh, 1989]. The physical explanation for the apparent weakness of the target is not known; current popular hypotheses are acoustic fluidization [Melosh, 1979], thermal softening [O'Keefe and Ahrens, 1999], and friction melting [Spray and Thompson, 1995]. Numerical simulations demonstrate that the choice of strength model has a strong influence on the precise shape of structural 
uplift across a crater [Wünnemann et al., 2005; Bray et al., 2007; Stewart and Senft, 2007]. Hence, the geometry of the uplift at Chicxulub shown here is of great importance for validating effective strength models, testing mechanisms for weakening the target, and future dynamic modeling of the Chicxulub crater.

\section{CONCLUSIONS}

We have used tomographic inversions of travel-time and gravity data to construct a new model of structural uplift beneath the Chicxulub impact crater. The final model shows a broad 80-km wide, zone of structural uplift, in which the amount of uplift decreases from the center outwards. A narrow, 15-25 km wide, high-velocity-zone is interpreted as lower-crustal rocks that have been uplifted between 10 and $30 \mathrm{~km}$ during crater formation. The geometry of the uplift beneath the Chicxulub crater will be useful in future attempts to distinguish between different strength models for large-crater collapse, and calibrate dynamic models for the formation of the Chicxulub impact crater.

\section{ACKNOWLEDGMENTS}

Both the 1996 and 2005 experiments were jointly funded by the Natural Environment Research Council (NERC) and the National Science Foundation (NSF). We thank Gail Christeson and Anneka Smith for supplying their travel-time picks. Manuscript support provided by Jackson School of Geosciences and Geology Foundation at UT Austin. UTIG contribution no. XXXX. IARC contribution no. 2007-0450.

\section{Figure 1}

Solid black lines show the 2005 marine seismic reflection survey and dashed black lines show the 1996 survey. Small white and black dots show the location of offshore and onshore 
seismometers for the 2005 and 1996 survey respectively. Large white dots are existing drill sites from which samples were used in this study: Yaxcopoil-1 (Yax-1) and Yucatan-6 (Y-6). Positions are superimposed on a Bouguer gravity map compiled by Styles [2006]. The white dashed rectangle illustrates the extent of our $3 \mathrm{D}$ velocity model and red lines show the location of 2D slices in Fig. 3 and 4.

\section{Figure 2}

Models of Chicxulub redrawn from a) Sharpton et al. [1996], and b) Hildebrand et al. [1998] re-scaled with a Vertical Exaggeration (V.E.) of 2. Both models are constructed using gravity, magnetic, and drill hole data, and model b) also uses constraints from seismic data.

\section{Figure 3}

Slices through a) final velocity model obtained from inversion of the travel-time data only, and b) final velocity model obtained from a combined inversion of both the travel-time and gravity data. The NS-oriented slices selected for illustration are at $\mathrm{X}=-18 \mathrm{~km},-12 \mathrm{~km}$ (near location of highest velocity), $-6 \mathrm{~km}$ and $0 \mathrm{~km}$ (center of crater). Contours are at 4.0, 4.5, 5.0, $5.5,6.0$ and $6.3 \mathrm{~km} \mathrm{~s}^{-1}$.

\section{Figure 4}

Slices through a) final velocity model obtained from inversion of the travel-time data only, and b) final velocity model obtained from a combined inversion of both the travel-time and gravity data. The EW-oriented slices selected for illustration are at $\mathrm{Y}=-4 \mathrm{~km}, 0 \mathrm{~km}$ (center of crater), $4 \mathrm{~km}$ (near location of highest velocity) and $8 \mathrm{~km}$. Contours are at 4.0, 4.5, 5.0, 5.5, 6.0 and $6.3 \mathrm{~km} \mathrm{~s}^{-1}$. 


\section{Figure 5}

One-dimensional starting model: velocity increasing with depth.

\section{Figure 6}

Geological interpretation, drawn at the same scale as the models in Fig. 2, with a V.E. of 2. Existing drill sites from which samples were used in this study are: Yaxcopoil-1 (Yax-1) and Yucatan-6 (Y-6). In the central crater beneath the melt sheet, rocks with velocities of $>6.3 \mathrm{~km}$ $\mathrm{s}^{-1}$ are interpreted as lower crustal in origin: solid black lines are from the $6.3 \mathrm{~km} \mathrm{~s}^{-1}$ contours in Fig. 3a at $X=-12 \mathrm{~km}$. Rocks with velocities of $6.0-6.3 \mathrm{~km} \mathrm{~s}^{-1}$ are interpreted as mid crustal in origin: solid grey line is from the $6.0 \mathrm{~km} \mathrm{~s}^{-1}$ contour in Fig. $4 \mathrm{~b}$ at $\mathrm{Y}=4 \mathrm{~km}$. The total width of the structural uplift is $\sim 80 \mathrm{~km}$, as defined by where the upper-crustal rocks are overturned underneath the crater's topographic peak ring.

\section{REFERENCES CITED}

Birch, F (1960), The velocity of compressional waves in rocks to 10 kilobars, Part $1, J$. Geophys. Res., 65, 1083-1102.

Bray, V. J., G. S. Collins, J. V. Morgan and P. M. Schenk (2007), The Effect of Target Properties on Impact Crater Morphology - Comparison of Craters on Icy and Silicate Bodies, paper presented at Bridging the Gap II: Effect of Target Properties on the Impact Cratering Process, Montreal, Canada.

Campos-Enriquez, J. O., H. F. Morales-Rodriquez, F. Dominquez-Mendez, and F. S. Birch (1998), Gauss's theorem, mass deficiency at Chicxulub crater (Yucatán, Mexico), and the extinction of the dinosaurs, Geophysics 63(5), 1585-1594.

Christeson, G. L., Y. Nakamura, R. T. Buffler, J. Morgan, and M. Warner (2001), Deep crustal structure of the Chicxulub impact crater, J. Geophys. Res., 106, 21751-21769. 
Christeson, G. L., G. S. Collins, J. V. Morgan, S. P.S. Gulick, P. J. Barton, M. R. Warner (2008), Mantle topography beneath the Chicxulub impact crater, Nature Geosci. (submitted).

Christensen, N. I., and D. M., Fountain (1975), Constitution of lower continental crust based on experimental studies of seismic velocities in granulite, Geol. Soc. Am. Bull., 86, 227236.

Collins, G. S., H. J. Melosh, J. V. Morgan, and M. R. Warner (2002), Hydrocode simulations of Chicxulub crater collapse and peak-ring formation, Icarus, 157, 24-33.

Collins, G. S., J. Morgan, P. Barton, G. L. Christeson, S. Gulick, J. Urrutia-Fucugauchi, M. Warner, and K. Wünnemann (2008), Dynamic modeling suggests asymmetries in the Chicxulub crater are caused by target heterogeneity, Earth Planet. Sci. Lett. (in review).

Dressler, B. O. (1984), The effects of the Sudbury event and the intrusion of the Sudbury Igneous Complex on the footwall rocks of the Sudbury Structure, in The Geology and Ore deposits of the Sudbury Structure, Spec. Vol. 1, Ontario Geological Survey, edited by E. Pye, A. J. Naldrett, and P. E. Giblin, pp. 97-136.

Ebbing, J., P. Janle, J. Koulouris, and B. Milkereit (2001), 3D gravity modeling of the Chicxulub impact structure, Planet. Space Sci., 49, 599-609.

Espindola, J. M., M. Mena, J. O. Fuente, and J. Campos-Enriquez (1995), A model of the Chicxulub impact structure (Yucatan, Mexico) based on gravity and magnetic signatures, Phys. Earth Planet. Interiors, 92, 271-278.

Gibson, R. L., and W. U. Reimold (2001), The Vredefort impact structure, South Africa (The scientific evidence and a two-day excursion guide), Memoir 92, 111 pp., Council for Geosci., Pretoria.

Gibson, R. L., W. U. Reimold, and G. Stevens, (1998), Thermal-metamorphic signature of an 
impact event in the Vredefort dome, South Africa, Geology, 26, 787-790.

Grieve, R. A. F. (Ed.) (2006), Impact structures in Canada, 210 pp., Geol. Ass. Can.

Grieve, R. A. F., and M. Pilkington (1996), The signature of terrestrial impact craters: AGSO, J. Austral. Geol. Geophys., 16, 399-420.

Grieve, R. A. F., W. U. Reimold, J. V. Morgan, U. Riller, and M. Pilkington, (2008), Observations and Interpretations at Vredefort, Sudbury and Chicxulub: Towards a composite model of a terrestrial impact basin, Meteor. Planet. Sci. (in press).

Gulick S. P. S., P. J. Barton, G. L. Christeson, J. V. Morgan, M. McDonald, K. MendozaCervantes, Z. F. Pearson, A. Surendra, J. Urrutia-Fucugauchi, P. M. Vermeesch, and M. R. Warner (2008), Importance of pre-impact crustal structure for the asymmetry of the Chicxulub impact crater, Nature Geosci., doi:10.1038/ngeo103.

Hildebrand, A. R., G. T. Penfield, D. A. Kring, M. Pilkington, Z. A. Camargo, S. B. Jacobsen, and W. V. Boynton (1991), Chicxulub crater: a possible Cretaceous/Tertiary boundary impact crater on the Yucatan Peninsula, Mexico, Geology, 19, 867-871.

Hildebrand, A. R, M. Pilkington, C. Ortiz-Aleman, R. E. Chavez, J. Urrutia-Fucugauchi, M. Connors, E. Graniel-Castro, and A. Camargo-Zanoguera (1998), Mapping Chicxulub crater structure with gravity and seismic reflection data, Geol. Soc. London Spec. Pub., 140, 177193.

Ivanov, B. A. (2005), Numerical modeling of the largest terrestrial meteorite craters, Solar Syst. Res., 39, 381-409.

Ivanov, B. A., A. T. Basilevsky, L. V. and Sazanova (1982), Formation of the central uplift in meteoritic craters [in Russian], Meteoritika, 40, 67-81.

James, R. S., J. M. Sweeney, and W. Peredery (1992), Thermobarometric studies on the Levack gneisses - footwall rocks to the Sudbury Igneous Complex, International 
Conference on Large Meteorite Impacts and Planetary Evolution, Abstracts, LPI Contribution No. 790, p. 41.

Kettrup, B., and A. Deutsch (2003), Geochemical variability of the Yucatán basement: constraints from crystalline clasts in Chicxulub impact impactites, Meteor. Planet. Sci., 38, 1079-1092.

Kring, D. A. (1995), The dimensions of the Chicxulub crater and impact melt sheet, $J$. Geophys. Res., 100, 16979-16986.

Lana, C., R. L. Gibson, and W. U. Reimold (2003), Impact tectonics in the core of the Vredefort dome, South Africa: Implications for central uplift formation in very large impact structures, Meteor. Planet. Sci., 38, 1093-1107.

Lopez-Ramos, E. (Ed.) (1979), Geologia de Mexico, 445 pp., Mexico City, UNAM.

McCarthy, T. S., I. G. Stanistreet, and L. J. Rob (1990), Geological studies related to the origin of the Witwatersrand basin and its mineralization - An introduction and a strategy for research and exploration, S. Afr. J. Geol., 93, 1-4.

Melosh, H. J. (1979), Acoustic fluidization: A new geologic process? J. Geophys. Res., 84, $7513-7520$.

Melosh, H. J. (Ed.) (1989), Impact cratering: A geologic process, 245 pp., Oxford Univ. Press, New York.

Menke, W. H., and D. H. Abbott (Eds.) (1991), Geophysical Theory, 454 pp., Columbia Univ. Press, New York.

Mooney, W. D., G. Laske, and T. G. Masters (1998), Crust 5.1: a global crustal model at 5x5 degrees, J. Geophys. Res., 103, 727-747.

Morgan, J., M. Warner, and the Chicxulub Working Group (1997), Size and morphology of the Chicxulub impact crater, Nature, 390, 472-476. 
Morgan, J. V., M. R. Warner, G. S. Collins, H. J. Melosh, and G. L. Christeson (2000), Peakring formation in large impact craters: Geophysical constraints from Chicxulub, Earth Planet. Sci. Lett., 183, 347-354.

Morgan, J. V., G. Christeson, and C. Zelt (2002), Testing the resolution of a 3D velocity tomogram across the Chicxulub crater, Tectonophysics, 355, 215-226.

O'Keefe, J. D., and T. Ahrens, (1999), Complex craters: Relationship of stratigraphy and rings to impact conditions, J. Geophys. Res., 104, 27091-27104.

Pilkington, M., and A. R. Hildebrand (2000), Three-dimensional magnetic imaging of the Chicxulub Crater, J. Geophys. Res., 105, 23479-23491.

Riller, U. (2005), Structural Characteristics of the Sudbury Impact Structure, Canada: impact induced and orogenic deformation, Meteor. Planet. Sci., 40, 1723-1740.

Sharpton, V. L., L. E. Marin, J. L. Carney, S. Lee, G. Ryder, B. C. Schuraytz, P. Sikora, P. D. Spudis (1996), Model of the Chicxulub impact basin based on evaluation of geophysical data, well logs, and drill core samples, in The Cretaceous-Tertiary Event and other Catastrophes in Earth History, Geol. Soc. Am. Spec. Paper, vol. 307, edited by G. Ryder, D. Fastovsky, and S. Gartner, pp. 55-74.

Spray, J. G., and L. M. Thompson (1995), Frictional melt distribution in a multi-ring impact basin, Nature, 373, 130-132.

Stewart, S. T., and L. E. Senft (2007), Frictional melting and complex crater collapse, paper presented at Bridging the Gap II: Effect of Target Properties on the Impact Cratering Process, \#8021, Montreal, Canada.

Styles, E. (2006), Chicxulub: An analysis of new gravity data, Masters thesis, 122 pp., Imperial College London, UK. 
Vermeesch, P. M. (2006), Geophysical study of the Chicxulub impact crater, Ph.D. thesis, 418 pp., Imperial College London, UK.

Vermeesch, P. M., and J. V. Morgan (2004), Chicxulub central crater structure: Initial results from physical property measurements and combined velocity and gravity modeling, Meteor. Planet. Sci., 39, 1019-1034.

Vermeesch, P. M., J. V. Morgan, G. Christeson, and P. Barton (2008), 3D joint inversion of travel-time and gravity data across the Chicxulub impact crater, J. Geophys. Res. (in prep).

Visnevsky, S., and A. Montanari (1999), Popigai impact structure (Arctic Siberia, Russia): Geology, petrology, geochemistry and geochronology of glass-bearing impactites, in Large Meteorite Impacts and Planetary Evolution II, Geol. Soc. Am. Spec. Paper, vol. 339, edited by B. O. Dressler, and V. L Sharpton, pp. 19-60.

Wünnemann, K., J. V. Morgan, and H. Jödicke (2005), Is Ries crater typical for its size? An analysis based upon old and new geophysical data and numerical modeling, In Large Meteorite Impacts III, Geol. Soc. Am. Spec. Paper, vol. 384, edited by T. Kenkmann, F. Horz, and A. Deutsch, pp. 67-84.

Yhap, C. (2007), Stratigraphic uplift beneath the Chicxulub impact crater: Resolution testing, MSci Thesis, Imperial College London, UK.

Zelt, C. A., and P. J. Barton (1998), Three-dimensional seismic refraction tomography: A comparison of two methods applied to data from the Faeroe Basin, J. Geophys. Res., 103, 7187-7210. 


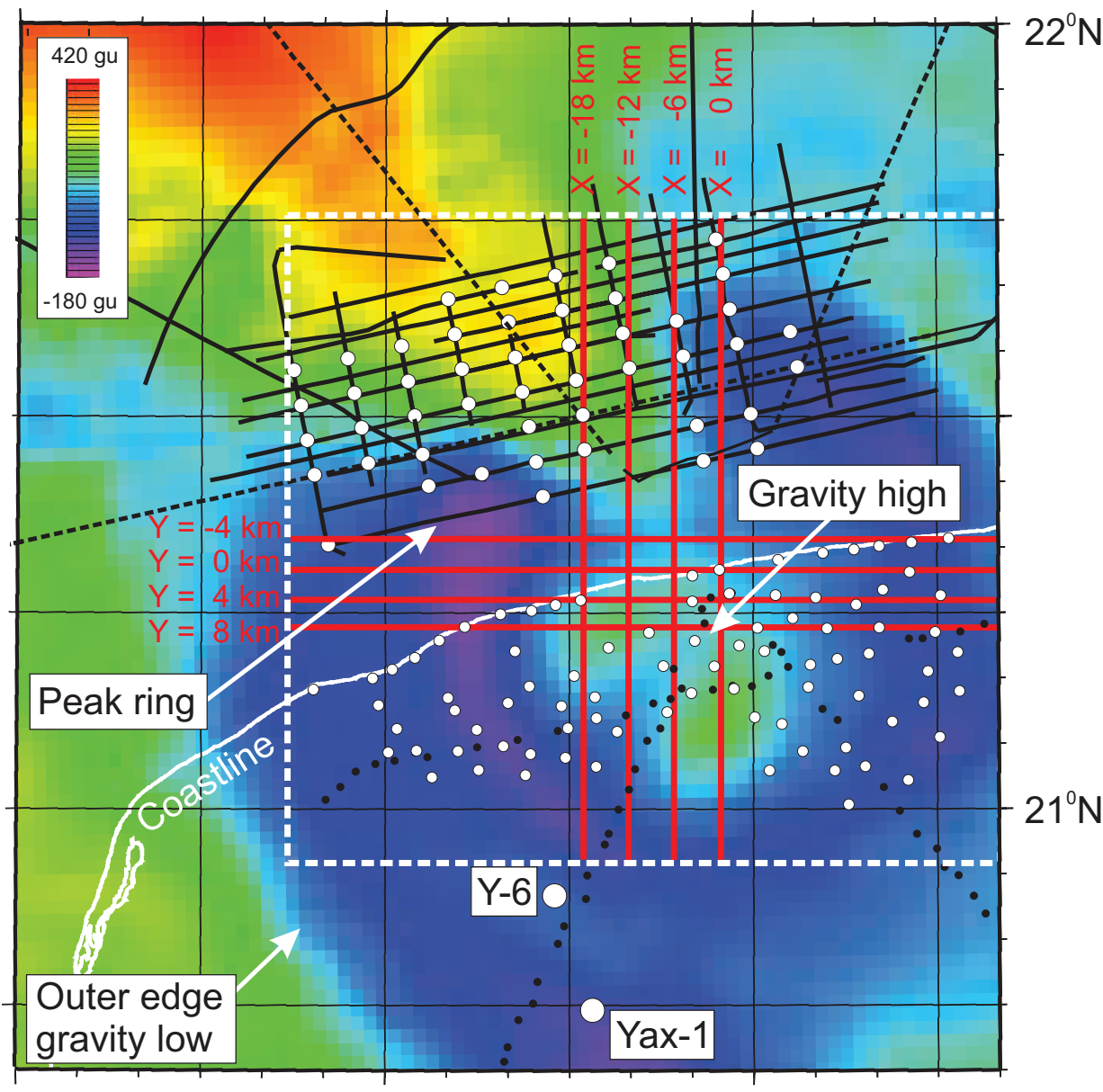




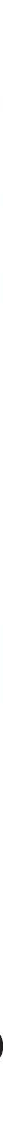

a)

Post-impact sediments

\section{Melt breccia}

b)

Post-impact sediments

Cretaceous rocks 
a)

y (km)

b)
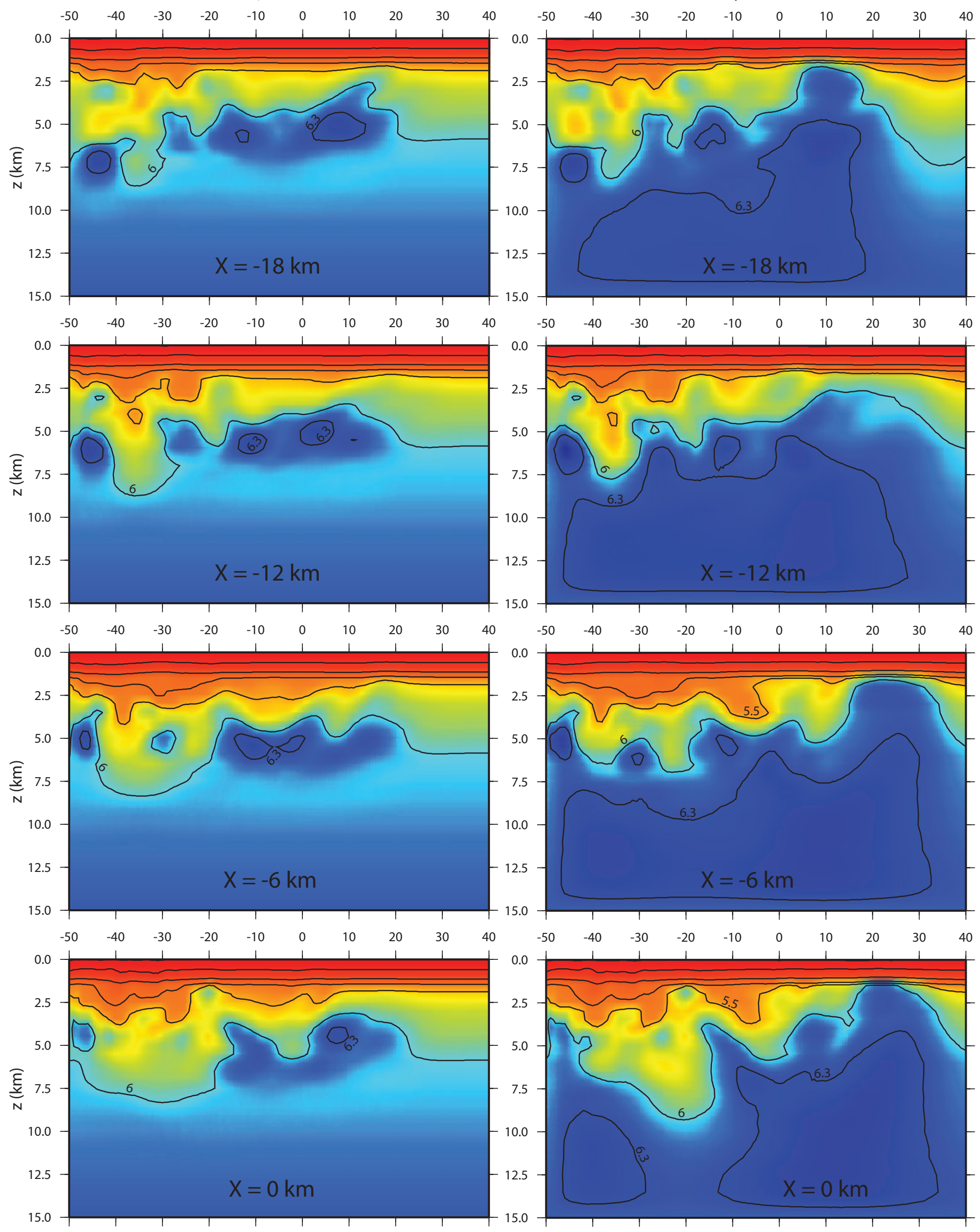

velocity $(\mathrm{km} / \mathrm{s})$

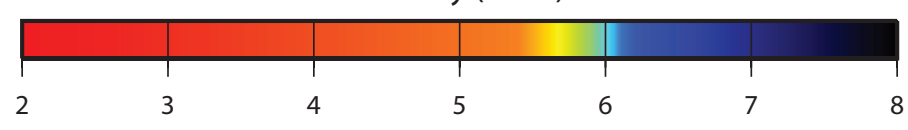


a)

$x(\mathrm{~km})$

b)
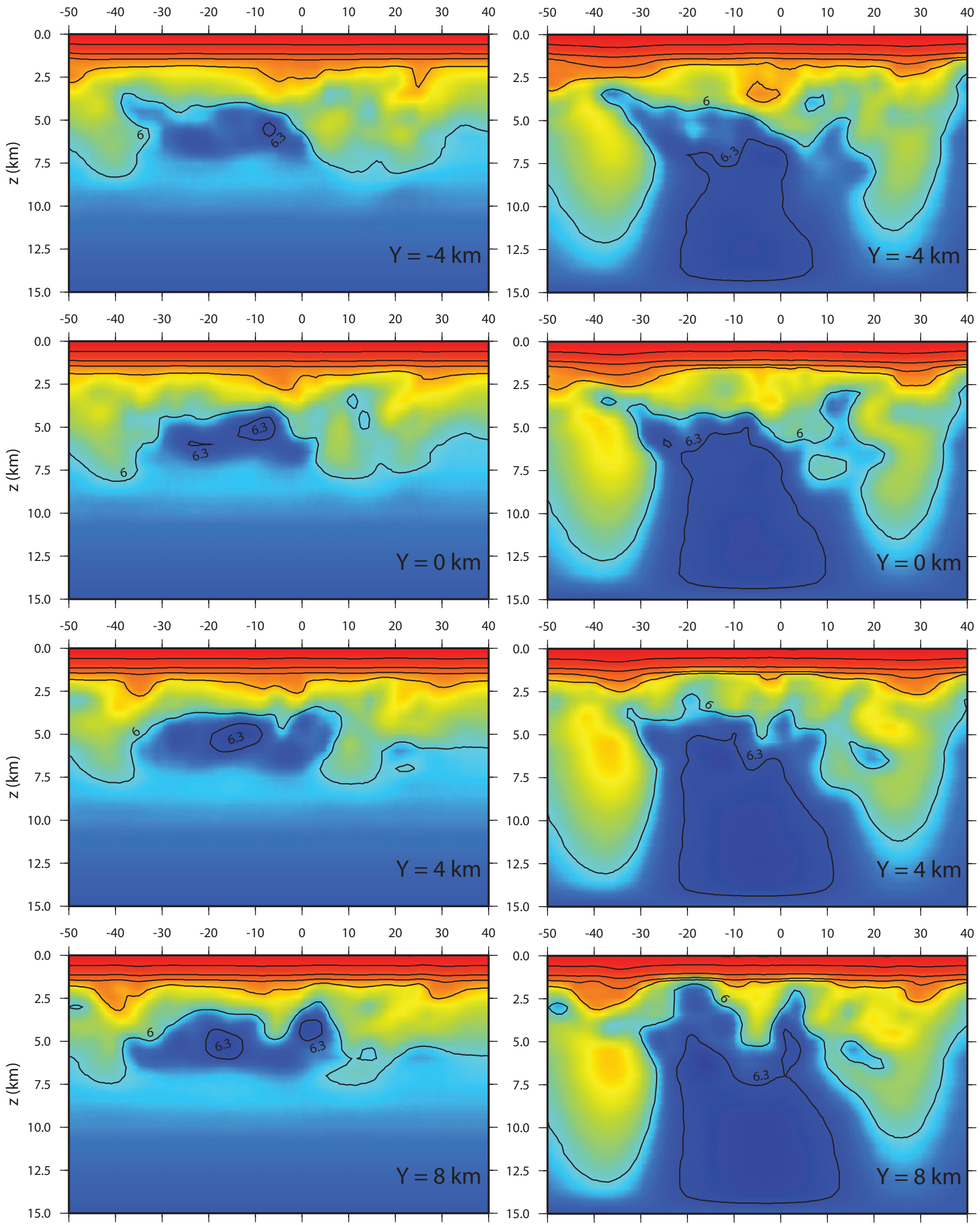

velocity $(\mathrm{km} / \mathrm{s})$

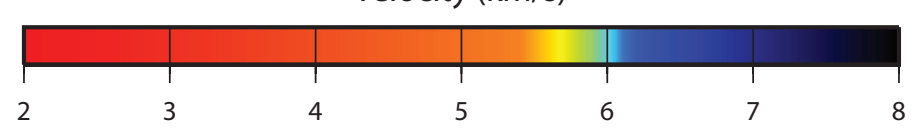


Starting velocity model

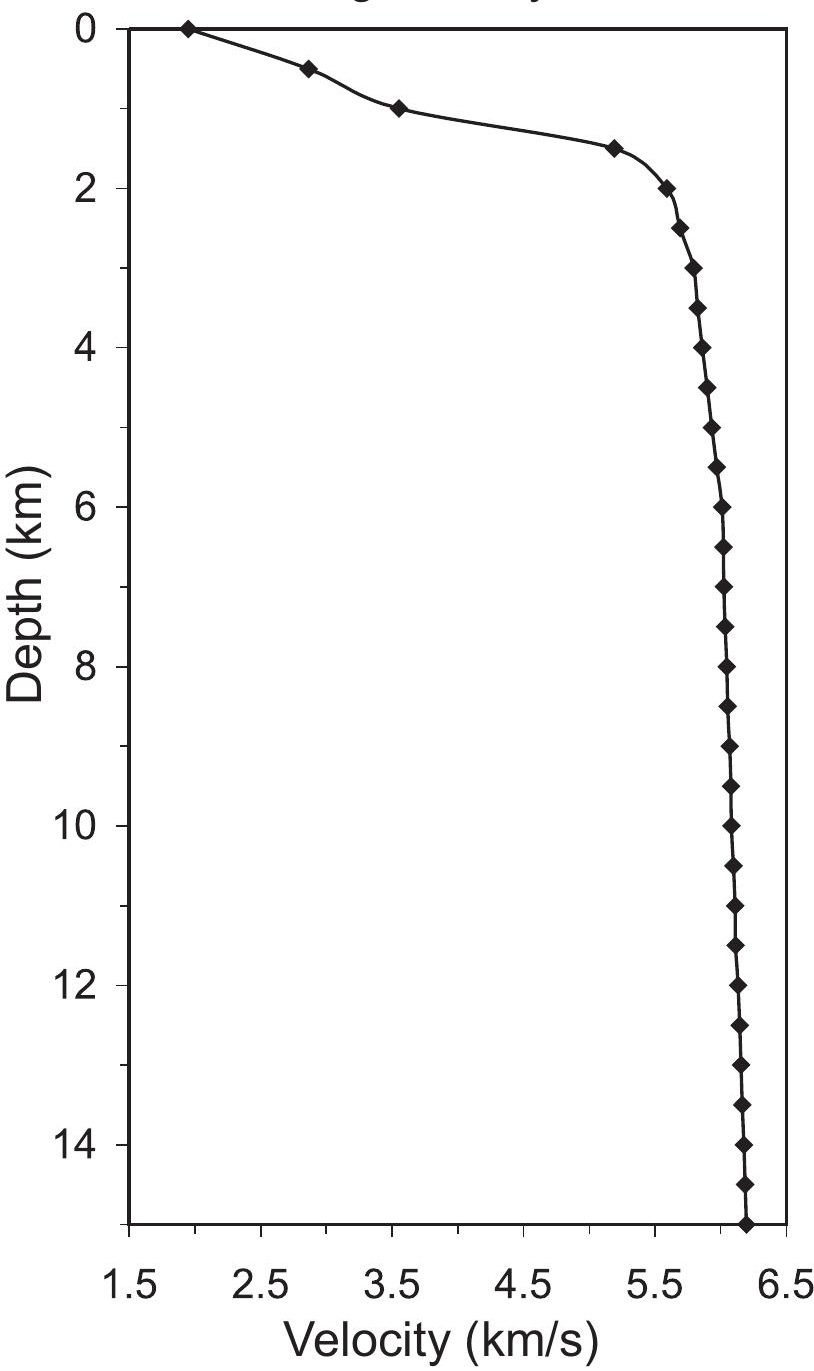




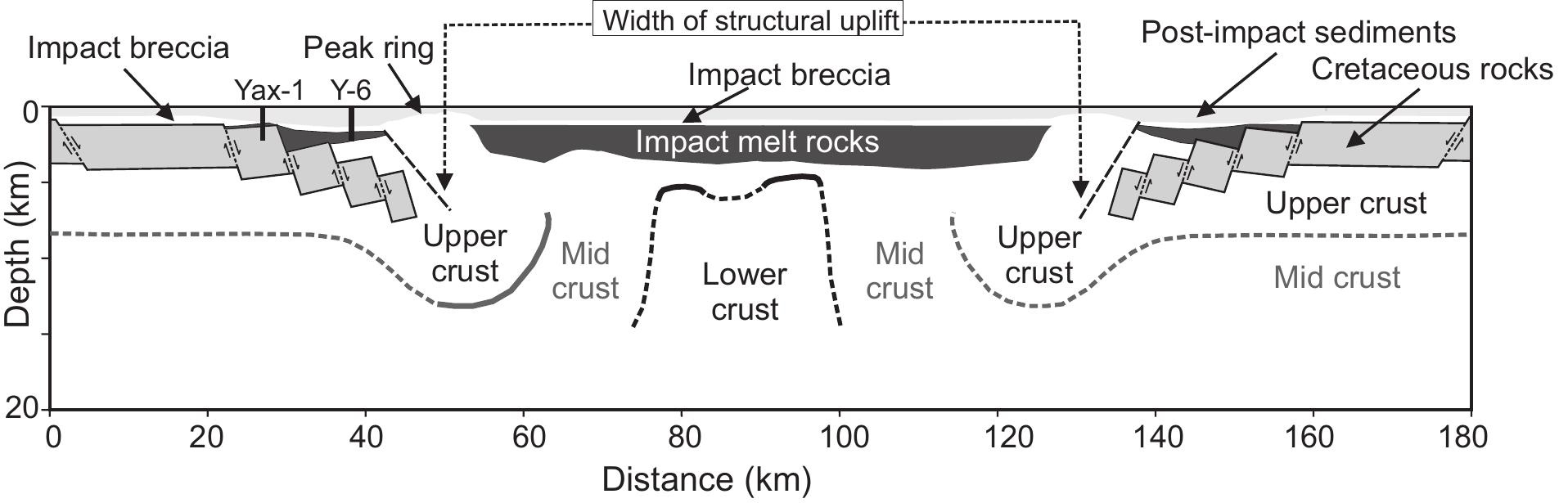

